\title{
Application of smart nano-WBM material for filtrate loss recovery in wellbores with tight spots problem: an empirical study
}

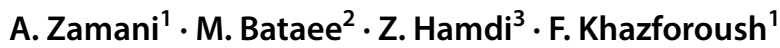

Received: 10 September 2017 / Accepted: 4 June 2018 / Published online: 12 June 2018

(c) The Author(s) 2018

\begin{abstract}
There is no deep understanding of the application of nanoparticles in water-based muds (WBM). Therefore, such study that helps to enhance the knowledge in the field of well stability using modern methods in an unforgiving industry is very much needed. The nanoparticles accumulate on the wellbore wall and due to their very small sizes, they seal the pores in the mud cake, which plasters the wellbore. This paper focuses on empirical aspects of using nano-bentonite for filter loss control. The current work was applied on a nano-drilling fluid to improve filtration characteristics of drilling fluid in the wellbore. Therefore, nano-bentonite WBM (size between 90 and $100 \mathrm{~nm}$ ) was introduced as the smart drilling fluid with abilities to overcome the tight spot problem in wellbores, which has been investigated in the paper. Three different drilling fluids were prepared using nano-bentonite clay with the main focus of enhancing those rheological features of the fluid expected to improve the mud characteristics, especially the plastering properties. Low pressure low temperature (LPLT) filter press test has been utilized to calculate the filter loss volume and the viscosity, yield point and gel strength of the understudy samples and the results have been compared. It was found that the filtration loss during the LPLT test was reduced by an overall average of $34 \%$ for all of the three samples, resulting in better filtration characteristics.
\end{abstract}

Keywords Drilling $\cdot$ Smart Nano fluid $\cdot$ Nano-WBM $\cdot$ Tight spot $\cdot$ Filtration Loss

\section{Introduction}

It is expected that the global oil demand increase in the coming years will be due to a leap in energy demand (Pourafshary and Azimpour et al. 2009; Kong and Ohadi 2010). As most of the oil wells around the world are at their maturity

A. Zamani

atefeh.zamani@gmail.com

M. Bataee

mahmood_bataee@hotmail.com

Z. Hamdi

h.zakaria@hw.ac.uk

F. Khazforoush

f.khazforoush@gmail.com

1 Department of Petroleum Engineering, Universiti Teknologi Petronas, Tronoh, Malaysia

2 Department of Petroleum Engineering, Asia Pacific University of Technology and Innovation, Kuala Lumpur, Malaysia

3 Department of Petroleum Engineering, Heriot Watt University, Putrajaya, Malaysia phases (Hite et al. 2004), the drilling stage is now even of more importance than before to minimize oil waste. As drilling fluid is, however, the most important element in a drilling process advanced well control methods focus on controlling the properties of the drilling fluid which is an advantage over conventional drilling methods. An efficient drilling operation depends mostly on the rheological properties of the drilling fluids (i.e., mud density, plastic viscosity, yield point, gel strength, and filtration loss) to ensure wellbore stability (Sadegh Hassani and Amrollahi et al. 2016; Sami 2016; Aftab and; Ismail et al. 2017). The widespread applications of nanotechnology in the energy sector have been widely extended to the oil and gas industry for various purposes including drilling in the recent years (Sabet and Hosseini et al. 2016). Nanotechnology is a branch of science which deals with the manipulation of atoms and molecules in a nano scale to produce macro scale matter with unique properties (Serrano and Rus et al. 2009). Some experts have introduced nano-drilling fluids with advanced features as the next generation of drilling fluids that will transform the drilling industry (Evdokimov and Eliseev et al. 2006; Amanullah and Al-Tahini 2009; Rao 2010; Li and; Xu et al. 2012; 
William and; Ponmani et al. 2014; Al-Yasiri and Al-Sallami 2015). Using nanoparticle drilling fluids, features including friction and wear reduction factor and rheology properties can be altered (Jahns 2014). Some of the advantages of nano-based drilling fluids are improving the efficiency of shale stabilization, enhancing mud cake, improving cement, and enhancing anti-corrosion capacity (Amanullah and AlTahini 2009; Kong and Ohadi 2010). Drilling fluid is expensive any loss will increase the corresponding costs, also the loss of drilling fluid in the formation lowers well productivity as skin factor increases (Pourafshary and Azimpour et al. 2009). Due to their nano size, the nanoparticles accumulate in the gaps between the larger particles, making lumps that prevent the flow in the matrix (Wilson 2012).

During the drilling operation, formation properties such as formation porosity and permeability control fluid flow in the formation. However, other factors such as the hydrostatic pressure profile produced by the drilling fluid column and the respective fluid pressure around the wellbore are more important variables. Fluid flow is in the direction of high pressure to low pressure, therefore, the main job of the drilling fluid is to maintain the hydrostatic pressure in such a way that it is higher than the formation pressure that prevents a kick and a blowout. Therefore, avoiding formation fluid loss is a better option than remedying treatments to reduce the related risks and costs.

When the drilling fluids penetrate the near wellbore formation, a filter cake forms from the mixture of drilling fluid and the solids particles deposited on the wellbore wall. The thickness of the occurred filter cake affects well performance in various ways including, poor log quality, enhanced torque and drag (Al-Yasiri and Al-Sallami 2015; Al-Zubaidi and; Alwasiti et al. 2016), stuck pipe (Paiaman and Al-Anazi 2008; Al-Yasiri and Al-Sallami 2015), formation of tight spots, circulation loss and formation damage (Reed 1989; Wasan and Nikolov 2003) (Dardir and Ibrahime et al. 2014). To minimize excessive filtration loss into the formation and the resulting consequences such as listed above, an effective design with a thinner filter cake and lower permeability is required that is able to prevent invasion of the drilling fluid.

The two main types of drilling fluids are WBM and OBM (Caenn and Darley et al. 2017). To prepare the drilling mud, the current industry practice prefers to use macro material fluids referred to as lost circulation materials (LCMs) that offer limited features which increase drilling operation time and consequently costs (Zakaria and Husein et al. 2012). Between OBM and WBM common practice is utilizing WBM as it is cheaper and more environmentally friendly (Rodrigues and Lachter et al. 2006; Sadeghalvaad and Sabbaghi 2015) while OBM allowed by the law. However, although more effective, OBM is costly and causes damage to the environment (Akhtarmanesh and Shahrabi et al. 2013; Abduo and; Dahab et al. 2016). Therefore, this study proposes a newer approach by nanotechnology to replace OBM with nano-WBM drilling fluid. The material used in the current work is smart nano bentonite produced by enhancing the rheological properties of bentonite clay.

\section{Drilling fluids}

Drilling fluid also referred to as drilling mud are the fluids used during drilling operation for circulation purposes or during tripping pipe for balancing the formation fluid pressure and the borehole pressure (Schlumberger 1999a, b). A successful drilling operation depends on a proper drilling fluid as the most important component of the drilling process (Apaleke and Al-Majed et al. 2012). The overall cost of drilling a well is highly dependent on the total cost of the drilling mud (Zakaria and Husein et al. 2012) which in case of deep wells or complex formations is very important. Therefore, ensuring the effectiveness of drilling mud safeguards the efficiency of the drilling program that composes up to $80 \%$ of the total drilling expenditures (Shah et al. 2010) and onefourth of the total oil exploration (Ragab 2014). The dubbed problems are more visible in the case of high pressure and temperature (HPHT) wells as the rheology changes is more sensitive at higher pressure and temperature (Amani 2012; Amani and Al-jubouri 2012; Elochukwu and; Gholami et al. 2017). The rheology properties of the drilling fluids can be controlled by appropriate additives.

\section{Nanotechnology in energy sector}

Nanotechnology is the science of producing nanomaterials with nano-size particles (e.g. 1 to 100 nanometers) (Cheraghian and Hendraningrat 2016). Surface engineering has made nanoparticles easily available to many sciences including but not limited to physics, chemistry, biology, electronics, medicine, chemical engineering, etc.(Rao 2010) (Tohver and Chan et al. 2001). It has been used for almost half a century in the oil and gas industry overall (Cocuzza and Pirri et al. 2011; Li and; Xu et al. 2012) including its application to exploration (i.e., to improve sensor sensitivity) and production (i.e., scale inhibitors, nanostructured separators) (Evdokimov and Eliseev et al. 2006).

However, only recently the applications of nanotechnology in drilling operations have been proposed for activities such as material for fluid loss control, stabilizing borehole, improving cementing quality, improving well perforation, etc. (Srivatsa and Ziaja 2011). Unfortunately, most of those applications have been in research scale as the latest economic situation in the industry has limited their introduction to field application. 


\section{Nano drilling fluid}

Nanotechnology has opened new doors for production of products with customized specifications that were previously considered impossible. Nanoparticles not only provide the incentives for synthesizing nano materials but also help reduce manufacturing costs (Dutta and Lawson et al. 2006). Nanotechnology provides a platform for customizing the rheology of the drilling mud as nanoparticles can make the solution more stable, and therefore more efficient (Miranda and Lara et al. 2012). By rearranging the molecules of the drilling mud in nanoscale it is possible to maintain the required fluid size, densities, and viscosities as per requirements for each drilling scenarios. Nano fluids can improve the effectiveness of oil exploration in remote places under complex conditions by providing a better well stability (Cocuzza and Pirri et al. 2011) which reduce the corresponding costs and time, 2 factors that are very important in the drilling process.

\section{Hydrostatic pressure}

Hydrostatic pressure is the pressure exerted by the column of the drilling fluid in the annulus and the drilling string at a given point (Schlumberger 1999a, b). Hydrostatic pressure is a function of the mud weight and the vertical depth and is calculated from the formula below:

Hydrostatic pressure $=$ pressure gradient $(\mathrm{psi} / \mathrm{ft})$

$$
\times \text { true vertical depth }(\mathrm{ft})
$$

where:

Pressure gradient $(\mathrm{psi} / \mathrm{ft})=0.052 \times$ weight of mud $(\mathrm{PPG})$

\section{Wellbore stability}

The stability of the wellbore is the factor that determines the gauge size, shape and integration. Well stability is the result of the drilling mud and the rock interactions (Zhang and Jia et al. 2015). To gain well stability water sensitivity should be controlled which can be done by reducing the interface contact between the water phase and the shale to eliminate unwanted interactions (Munshi and Singh et al. 2008; McElfresh and; Holcomb et al. 2012).

\section{Methodology}

\section{Sample preparation}

The lab experiments were conducted using three samples of WBM with the following mud weights: WBM bentonite
(10 PPG), WBM bentonite (11 PPG) and WBM bentonite (12 PPG). To prepare the mud for each of the samples first bentonite was mixed with water in the multi mixer device and then the right amount of barite was added to it and the final solution was mixed for $10 \mathrm{~min}$. The amount of barite required to increase the fluid density in the experiment was calculated from the following formula for each sample:

Barite $=1470 \times\left[\left(w_{2}-w_{1)} /\left(35-w_{2}\right)\right]\right.$

where: $w_{1}=$ initial mud weight in $\mathrm{lb} / \mathrm{gal}, w_{2}=$ desired mud weight in $\mathrm{lb} / \mathrm{gal}$.

The following table summarizes the mixing amount (Table 1).

A density caliper device was used to find the actual density of the base that is found to be 8.7 PPG. In the next stage, a viscometer was used to measure rheology characteristics of the samples including viscosity, yield point, and gel strength.

\section{Viscosity}

Viscosity is the indicator of internal the resistance of a fluid to flow. Viscosity is calculated by dividing the shear stress by shear rate. Viscosity is usually reported in centipoise (100 centipoise (cp) $=1$ poise).

Viscosity $(\mathrm{cp})=\frac{\text { shear stress }(\text { Dyne.Sec })}{\text { shear rate }\left(\mathrm{cm}^{2}\right)}=\frac{\tau}{\gamma}$

\section{Yield point}

Yield point (YP) is defined as the initial resistance of a fluid to flow which is the result of electrochemical interactions between fluid's particles. Yield point values are used to evaluate the capability of a fluid to transport debris out of the annulus, therefore higher readings are preferable. On a viscometer, yield point is calculated from the following formula:

$\mathrm{YP}=\theta_{300}-\mathrm{PV}, \mathrm{PV}=\left(\theta_{600}-\theta_{300}\right)$

$\theta$ being the shear stress reading at speeds 600 RMP and 300RMP from Fann model 35 viscometer tool which is also the industry standard equipment for calculating yield point that is used in this study.

Table 1 Sample component mixture amount

\begin{tabular}{llcl}
\hline WBM & Bentonite $(\mathrm{g})$ & Barite $(\mathrm{g})$ & Water $(\mathrm{ml})$ \\
\hline $10 \mathrm{PPG}$ & 22.6 & 76.44 & 350 \\
$11 \mathrm{PPG}$ & 22.6 & 140.87 & 350 \\
$12 \mathrm{PPG}$ & 22.6 & 210.90 & 350 \\
\hline
\end{tabular}




\section{Plastic viscosity}

In Bingham plastic model plastic viscosity (PV) is the viscosity of a drilling mud under infinite shear rate (e.g., where shear rate is equal to zero).

\section{Gel strength}

Gel strength is the indicator of a fluid's ability to suspend drilling debris while the drilling fluid is resting. It is calculated by measuring the shear stress of the mud at low shear rates. Normally gel strength is calculated once after $10 \mathrm{~s}$ and once after 10 min while drilling fluid is in static conditions. A high difference between gel strength values at the intervals shows an unstable structure buildup, therefore, lower differences are preferred.

The results of rheology features of the understudy gels are reported in Table 2 as per below:

The next stage is to conduct the LPLT filter press test. The filtration loss volume is calculated in $1 \mathrm{~min}$ intervals for all the 3 nano mud samples as well as for the base mud. The results are summarized in the following table (Table 3).

Table 2 Mud characteristic

\begin{tabular}{|l|l|l|l|l|l|l|}
\hline \multicolumn{2}{|c|}{} & $\begin{array}{c}\mathbf{8 . 7} \\
\text { PPG } \\
\text { Marameters }\end{array}$ & 10 PPG MUD & 11 PPG MUD & 12 PPG MUD & \\
\hline \multirow{4}{*}{ Rotor reading } & $\theta 600$ & 27 & 28 & 33 & 38 & Increase \\
\cline { 2 - 8 } & $\theta 300$ & 19 & 20 & 22 & 26 & Increase \\
\hline Viscosity (cp) & 7 & 8 & 11 & 12 & Increase \\
\hline Yield point (YP) & 12 & 12 & 11 & 14 & \\
\hline \multirow{4}{*}{ Gel strength } & 10 seconds & 11 & 13 & 15 & 16 & Increase \\
\cline { 2 - 8 } & 10 minutes & 24 & 29 & 31 & 39 & Increase \\
\hline
\end{tabular}

Table 3 Filtration loss result from LPLT press test

\begin{tabular}{|c|c|c|c|c|c|c|c|c|c|}
\hline \multirow[t]{2}{*}{ Time (Minutes) } & \multicolumn{8}{|c|}{ Filtration Loss (ml) } & \multirow{2}{*}{$\begin{array}{l}\text { Average } \\
\text { difference } \\
(\%)\end{array}$} \\
\hline & $\begin{array}{l}\text { 10PPG } \\
\text { Normal MUD }\end{array}$ & $\begin{array}{l}\text { 10PPG } \\
\text { Nano-WBM }\end{array}$ & $\begin{array}{l}\text { Average } \\
\text { difference } \\
(\%)\end{array}$ & $\begin{array}{l}11 \mathrm{PPG} \\
\text { normal } \\
\text { MUD }\end{array}$ & $\begin{array}{l}\text { 11PPG } \\
\text { Nano- } \\
\text { WBM }\end{array}$ & $\begin{array}{l}\text { Average } \\
\text { difference } \\
(\%)\end{array}$ & $\begin{array}{l}12 \mathrm{PPG} \\
\text { normal } \\
\text { MUD }\end{array}$ & $\begin{array}{l}12 \mathrm{PPG} \\
\text { Nano- } \\
\text { WBM }\end{array}$ & \\
\hline 1 & 4.2 & 3 & 40 & 2.4 & 2 & 20 & 4.8 & 3.6 & 33.3 \\
\hline 2 & 6.4 & 4.8 & 33.3 & 3.8 & 3.2 & 18.75 & 7.5 & 5.6 & 33.9 \\
\hline 3 & 8.1 & 6.2 & 30.6 & 5.4 & 4.4 & 22.7 & 9.2 & 6.8 & 35.3 \\
\hline 4 & 9.2 & 6.8 & 35.3 & 7.3 & 5.4 & 35.2 & 11 & 8 & 37.5 \\
\hline 5 & 10.3 & 7.6 & 35.5 & 8.6 & 6.4 & 34.4 & 12.15 & 9 & 35 \\
\hline 6 & 11.4 & 8.4 & 35.7 & 9.2 & 7.2 & 27.7 & 13.2 & 9.8 & 34.7 \\
\hline 7 & 12.3 & 9.2 & 33.7 & 10.1 & 8 & 26.25 & 14.2 & 10.6 & 34.0 \\
\hline 8 & 13.9 & 9.9 & 40.4 & 10.5 & 8.8 & 19.3 & 15.6 & 11.6 & 34.4 \\
\hline 9 & 14.4 & 10.4 & 38.4 & 11.1 & 9.5 & 16.8 & 16.8 & 12.4 & 35.4 \\
\hline 10 & 14.8 & 10.9 & 35.7 & 11.9 & 10.2 & 16.7 & 17.5 & 13 & 34.6 \\
\hline 11 & 16.4 & 11.5 & 42.6 & 12.4 & 11.1 & 11.7 & 18.2 & 13.6 & 33.8 \\
\hline 12 & 17.6 & 12.4 & 41.9 & 15.5 & 11.6 & 33.6 & 19.2 & 14 & 37.1 \\
\hline 13 & 18.6 & 13.1 & 41.9 & 16.9 & 12.1 & 39.6 & 19.8 & 14.6 & 35.6 \\
\hline 14 & 19.6 & 13.8 & 42.0 & 17.8 & 12.6 & 41.2 & 20.6 & 15.3 & 34.6 \\
\hline 15 & 20 & 14.4 & 38.9 & 20.2 & 13.3 & 51.8 & 21.6 & 16 & 35 \\
\hline 16 & 20.2 & 14.8 & 36.4 & 19.7 & 13.9 & 42 & 22.5 & 16.4 & 37.2 \\
\hline 17 & 20.8 & 15.2 & 36.8 & 20.3 & 14.3 & 42 & 23.2 & 16.9 & 37.37 \\
\hline 18 & 21.2 & 16 & 32.5 & 20.874 & 14.7 & 42 & 23.5 & 17.3 & 35.8 \\
\hline 19 & 23.4 & 16.3 & 43.5 & 21.442 & 15.1 & 42 & 24.2 & 17.7 & 36.7 \\
\hline 20 & 23.8 & 16.6 & 43.3 & 21.868 & 15.4 & 42 & 24.5 & 18 & 36.1 \\
\hline total average difference & & & 37.9 & & & 31.3 & & & 35.3 \\
\hline
\end{tabular}




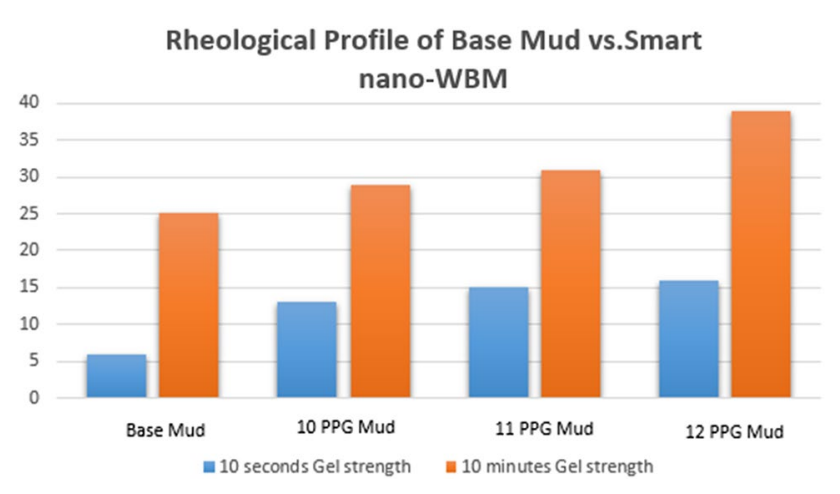

Fig. 1 Gel strength profile of base mud vs smart nano-WBM

\section{Discussion}

While OBM has been the standard drilling mud practice in the past, the high costs and environmental damages of OBM are inevitable. On the other hand, one of the main constraints of WBM is its water sensitivity that is problematic especially in case of complex formations. Therefore, a need for innovation in the field of drilling engineering is felt. In this study, nano bentonite which is referred to here as smart nano-WBM is introduced as a possible solution to overcome the problems caused by both OBM and WBM. The results of LPLT press test were compared for both WBM and smart nano-WBM. As it is obvious from Table 2 in the 20-min test window the filtration loss for 10 PPG, 11 PPG and 12 PPG muds using nano bentonite is reduced by 38,31 and $35 \%$ in order. The nano particles have the tendency to accumulate on the wellbore wall and due to their very small size, the particles seal the pores in the mud cake which can be translated as the plastering effect. While smart nano-WBM has improved the gel strength of the nano samples in comparison with the original mud, there is not a clear trend for viscosity or yield. The high yield point of the smart nano-WBM samples is the indicator of a good dynamic suspension of the drilling debris, and therefore efficient cleaning. The results of gel strength test (Fig. 1) shows a small difference between the 10-s gel and the 10-min gel for the understudy nano bentonite samples that indicates a stable structure buildup which is also an indicator of lower chances of hole failure during higher pressures.

\section{Conclusion}

The final outcome shows that using nano-particles filtration loss during the LPLT test was reduced by an overall average of $34 \%$ for all of the understudy samples. It seems that there is no special pattern for the relationship between the smart nano-WBM density and the filtration loss, however, there is a positive relationship between the filtration loss and the time in both normal and smart WBM. In all the cases as time goes on filtration loss using the smart nano-WBM is reduced. Therefore, bentonite nanoparticles increase the plastering effect of the drilling fluid in the wellbore as the results show a promising filtration loss effect. This will cause more stability in the well and is saving both time and money. Also according to the mud test using smart nanoWBM improves efficient cleaning.

\section{Future work and suggestion}

During the drilling process, up to $75 \%$ of the formation is composed of shale which is the cause of almost $90 \%$ of borehole problems due to the instability of the formation. WBM is not the best option for drilling in shale due to problems such as swelling, whereas OBM is an expensive option. More investigation is required on the application of nanoparticles on filter cakes in the field, which could be an idea for further advancements in this nanofluids field.

Open Access This article is distributed under the terms of the Creative Commons Attribution 4.0 International License (http://creativeco mmons.org/licenses/by/4.0/), which permits unrestricted use, distribution, and reproduction in any medium, provided you give appropriate credit to the original author(s) and the source, provide a link to the Creative Commons license, and indicate if changes were made.

\section{References}

Abduo MI, Dahab AS, Abuseda H, AbdulAziz AM, Elhossieny MS (2016) Comparative study of using water-based mud containing multiwall carbon nanotubes versus oil-based mud in HPHT fields. Egypt J Pet 25(4):459-464

Aftab A, Ismail AR, Ibupoto ZH (2017) Enhancing the rheological properties and shale inhibition behavior of water-based mud using nanosilica, multi-walled carbon nanotube, and graphene nanoplatelet. Egypt J Pet 26(2):291-299

Akhtarmanesh S, Shahrabi MJA, Atashnezhad A (2013) Improvement of wellbore stability in shale using nanoparticles. J Petrol Sci Eng 112:290-295

Al-Yasiri MS, Al-Sallami WT (2015) "How the drilling fluids can be made more efficient by using nanomaterials. Am J Nano Res Appl 3(3):41-45

Al-Zubaidi NS, Alwasiti AA, Mahmood D (2017) A comparison of nano bentonite and some nano chemical additives to improve drilling fluid using local clay and commercial bentonites. Egypt J Pet 26:811-818

Amani M (2012) The rheological properties of oil-based mud under high pressure and high temperature conditions. Adv Pet Explor Dev 3(2):21-30

Amani M, Al-jubouri MJ (2012) An experimental investigation of the the effects of ultra high pressures and temperatures on the rheological properties of water-based drilling fluids. Society of Petroleum Engineers, Richardson 
Amanullah M, Al-Tahini AM (2009) Nano-technology-its significance in smart fluid development for oil and gas field application. Society of Petroleum Engineers, Richardson

Apaleke AS, Al-Majed AA, Hossain ME (2012) Drilling fluid: state of the art and future trend. Society of Petroleum Engineers, Richardson

Caenn R, Darley HCH, Gray GR (2017) Chapter 1-introduction to drilling fluids. Composition and properties of drilling and completion fluids (seventh edition). Gulf Professional Publishing, Boston, pp 1-34

Cheraghian G, Hendraningrat L (2016) A review on applications of nanotechnology in the enhanced oil recovery part A: effects of nanoparticles on interfacial tension. Int Nano Lett 6(2):129-138

Cocuzza M, Pirri F, Rocca V, Verga F (2011). Is the oil industry ready for nanotechnologies? In: Offshore Mediterranean Conference

Dardir MM, Ibrahime S, Soliman M, Desouky SD, Hafiz AA (2014) Preparation and evaluation of some esteramides as synthetic based drilling fluids. Egypt J Petrol 23(1):35-43

Dutta S, Lawson R, Marcinko D (2006) How the nanotechnology revolution will affect cost management. J Corp Acc Finance 17(3):37-46

Elochukwu H, Gholami R, Sham Dol S (2017) An approach to improve the cuttings carrying capacity of nanosilica based muds. J Petrol Sci Eng 152:309-316

Evdokimov IN, Eliseev NY, Losev AP, Novikov MA (2006) Emerging petroleum-oriented nanotechnologies for reservoir engineering. Society of Petroleum Engineers, Richardson

Hite JR, Avasthi SM, Bondor PL (2004) Planning EOR Projects: paper SPE 92006 presented at the SPE International Petroleum Conference, Puebla, Mexico, November 8-9. Enhanced Oil Recovery Screening using

Jahns C (2014) Friction reduction by using nano-fluids in drilling (Master's thesis, Institutt for petroleumsteknologi og anvendt geofysikk)

Kong X, Ohadi M (2010) Applications of micro and nano technologies in the oil and gas industry-overview of the recent progress. Society of Petroleum Engineers, Richardson

Li L, Xu X, Sun J, Yuan X, Li Y (2012) Vital role of nanomaterials in drilling fluid and reservoir protection applications. Society of Petroleum Engineers, Richardson

McElfresh PM, Holcomb DL, Ector D (2012) Application of nanofluid technology to improve recovery in oil and gas wells. Society of Petroleum Engineers, Richardson

Miranda CR, Lara LSd, Tonetto BC (2012) Stability and mobility of functionalized silica nanoparticles for enhanced oil recovery applications. Society of Petroleum Engineers, Richardson

Munshi AM, Singh VN, Kumar M, Singh JP (2008) "Effect of nanoparticle size on sessile droplet contact angle. J Appl Phys 103(8):084315

Paiaman AM, Al-Anazi BD (2008) "Using nanoparticles to decrease differential pipe sticking and its feasibility in Iranian Oil fields. Oil Gas Business 33(10):192-198

Pourafshary P, Azimpour SS, Motamedi P, Samet M, Taheri SA, Bargozin H, Hendi SS (2009) Priority Assessment of Investment in Development of Nanotechnology in Upstream Petroleum Industry, Society of Petroleum Engineers, Richardson
Ragab AMS (2014) Mitigation of formation damage by designing a novel nanoparticles mud. Oil Gas Eur Mag 104-109

Rao Y (2010) Nanofluids: stability, phase diagram, rheology and applications. Particuology 8(6):549-555

Reed M (1989) Formation damage prevention during drilling and completion. SPE Centennial Symposium at New Mexico Tech. Society of Petroleum Engineers, Richardson

Rodrigues JdA, Lachter ER, de Sá CH, de Mello M, Nascimento RSV (2006) New Multifunctional Polymeric Additives for Water-Based Muds. Society of Petroleum Engineers, Richardson

Sabet M, Hosseini S, Zamani A, Hosseini Z, Soleimani H (2016). Application of nanotechnology for enhanced oil recovery: a review. Defect and Diffusion Forum. Trans Tech Publications Ltd, Zürich

Sadegh Hassani S, Amrollahi A, Rashidi A, Soleymani M, Rayatdoost S (2016) The effect of nanoparticles on the heat transfer properties of drilling fluids. J Petrol Sci Eng 146:183-190

Sadeghalvaad M, Sabbaghi S (2015) The effect of the TiO2/polyacrylamide nanocomposite on water-based drilling fluid properties. Powder Technol 272:113-119

Sami NA (2016) Effect of magnesium salt contamination on the behavior of drilling fluids. Egypt J Pet 25(4):453-458

Schlumberger (1999a) Oilfield glossary: hydrostatic pressure. Schlumberger, Houston

Schlumberger (1999b). Oilfield glossary: drilling fluid. Schlumberger, Houston

Serrano E, Rus G, García-Martínez J (2009) Nanotechnology for sustainable energy. Renew Sustain Energy Rev 13(9):2373-2384

Shah SN, Shanker NH, Ogugbue CC (2010) Future challenges of drilling fluids and their rheological measurements. In AADE fluids conference and exhibition, Houston, Texas

Srivatsa JT, Ziaja MB (2011) An experimental investigation on use of nanoparticles as fluid loss additives in a surfactant-polymer based drilling fluids. In: International Petroleum Technology Conference

Tohver V, Chan A, Sakurada O, Lewis JA (2001) Nanoparticle engineering of complex fluid behavior. Langmuir 17(26):8414-8421

Wasan DT, Nikolov AD (2003) Spreading of nanofluids on solids. Nature 423(6936): 156-159

William JKM, Ponmani S, Samuel R, Nagarajan R, Sangwai JS (2014) Effect of $\mathrm{CuO}$ and $\mathrm{ZnO}$ nanofluids in xanthan gum on thermal, electrical and high pressure rheology of water-based drilling fluids. J Petrol Sci Eng 117:15-27

Wilson A (2012) Preliminary test results of nano-based fluids reveal benefits for field application. J Pet Technol 64(11):104-108

Zakaria M, Husein MM, Harland G (2012) Novel Nanoparticle-Based Drilling Fluid with Improved Characteristics, Society of Petroleum Engineers, Richardson

Zhang Q, Jia W, Fan X, Liang Y, Yang Y (2015) A review of the shale wellbore stability mechanism based on mechanical-chemical coupling theories. Petroleum 1(2):91-96

Publisher's Note Springer Nature remains neutral with regard tojurisdictional claims in published maps and institutional affiliations. 